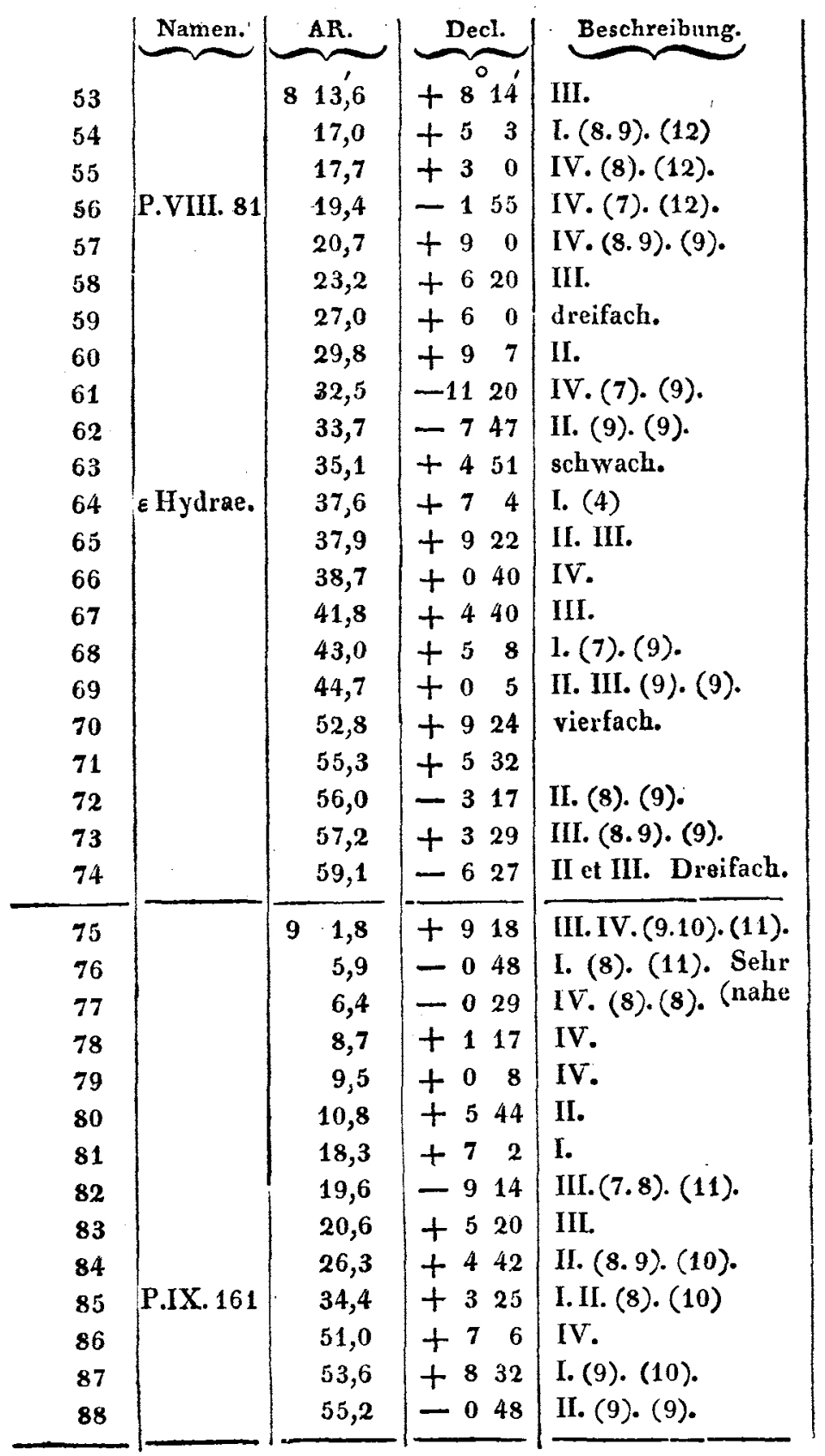

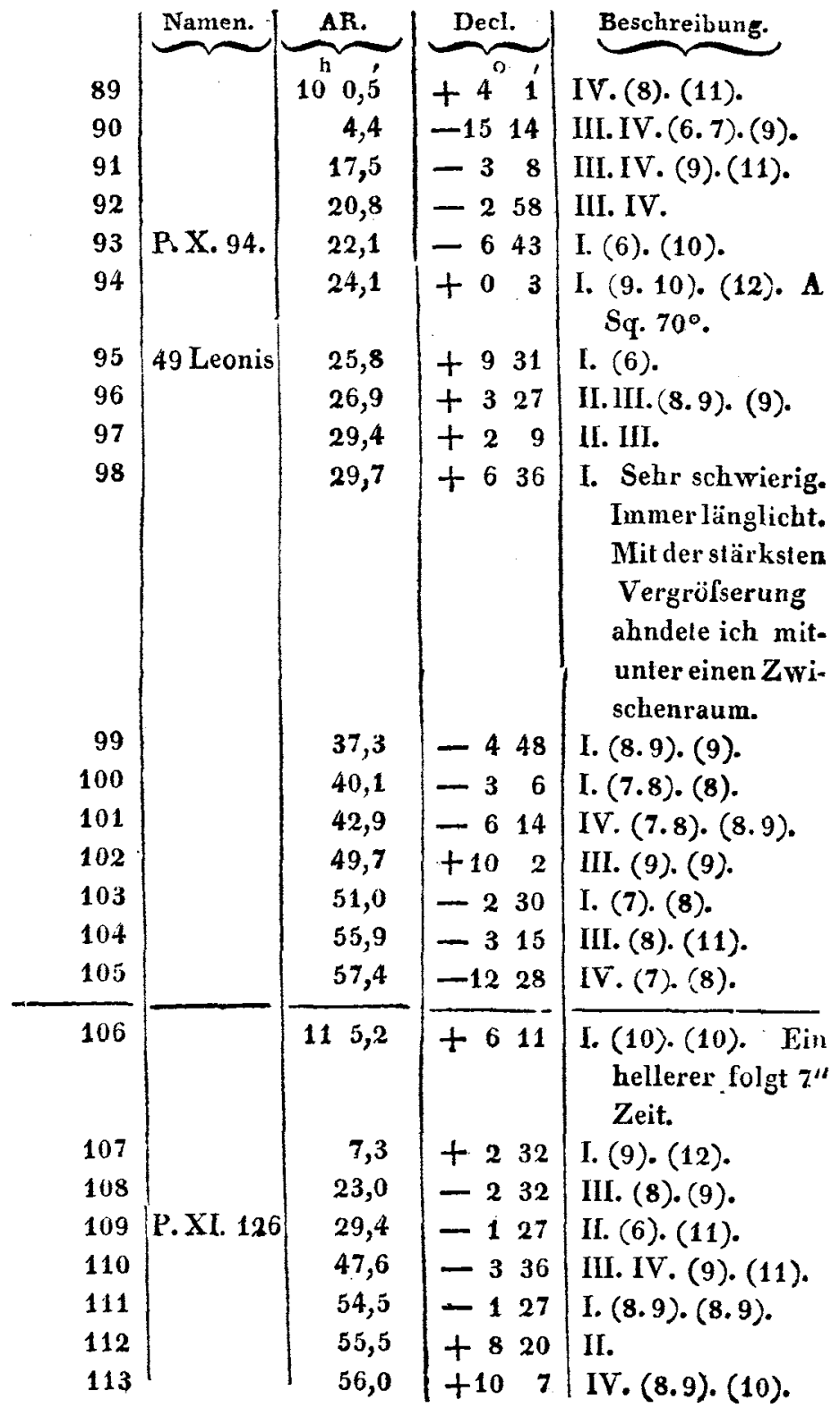

Dorpat, den 20 sten März 1825.

\title{
W. Struve.
}

Sternbedeckungen beobachtet zu Speier in den 'Jahren 1823 und 1824.

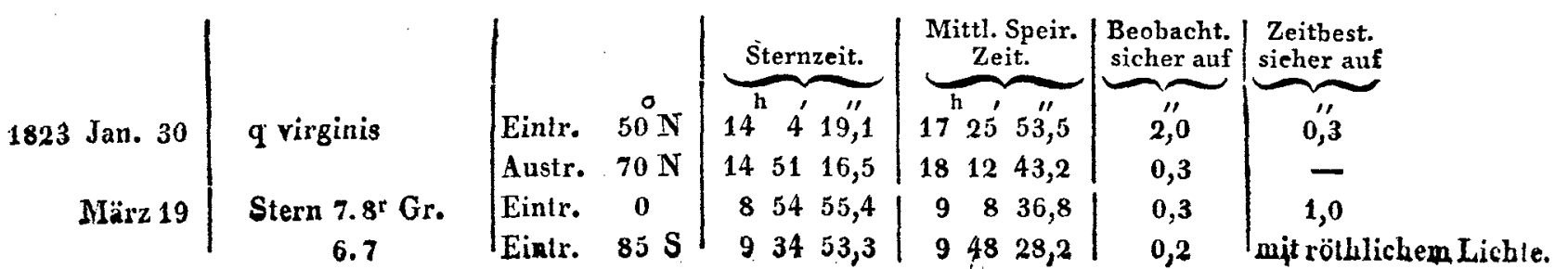




\begin{tabular}{|c|c|c|c|c|c|c|c|}
\hline \multirow{3}{*}{18.23 März 19} & \multirow[b]{2}{*}{ Siern $6^{r}$ Gr. } & \multirow{2}{*}{\multicolumn{2}{|c|}{ Eintr. $40^{\circ} \mathrm{N}$}} & Sternzeit. & $\begin{array}{l}\text { Mittl. Speir. } \\
\text { Zeit. }\end{array}$ & \multirow{2}{*}{$\underbrace{\begin{array}{c}\text { Beobacht. } \\
\text { sicher auf }\end{array}}_{0,3}$} & \multirow{2}{*}{$\underbrace{\begin{array}{c}\text { Zeitbest. } \\
\text { sicher auf }\end{array}}$} \\
\hline & & & & $10^{h} 7^{\prime} 37^{\prime \prime}, 8$ & $10^{\mathrm{h}} 21^{\prime} 7^{\prime}, 3$ & & \\
\hline & 8 & Eintr. & $5 \mathrm{~N}$ & $\begin{array}{lll}10 & 10 & 23,3\end{array}$ & 102352,3 & 2,0 & \\
\hline & 8 & Eintr. & $45 \mathrm{~N}$ & 103148,7 & $1045 \quad 14,3$ & 0,5 & \\
\hline April 14 & 7 & Eintr. & $70 \mathrm{~N}$ & $\begin{array}{lll}10 & 9 & 20,9\end{array}$ & $840 \quad 36,5$. & 0,2 & 0,5 \\
\hline 15 & 8 & Eintr. & $20 \mathrm{~S}$ & $11 \quad 1 \quad 14,4$ & 92825,6 & 0,5 & 0,3 \\
\hline 19 & 6. $7 \mathrm{r}$ & Eintr. & $3 \mathrm{~N}$ & 113135,8 & $942 \quad 58,4$ & 0,2 & 1,0 \\
\hline May 18 & 69 leunis & Eintr. & $40 S$ & 132334,0 & $940 \quad 36,7$ & 0,2 & 0,3 \\
\hline Aug. 3 & $6 r$ & Eintr. & $45 \mathrm{~N}$ & $\begin{array}{lll}23 & 14 & 3,0\end{array}$ & 142644,0 & 3,0 & 0,3 \\
\hline & & Austr. & $40 \mathrm{~N}$ & $23 \quad 4957,1$ & 15232,3 & 0,5 & $\longrightarrow$ \\
\hline Oct. 10 & 7. 8 & Eintr. & $\mathbf{0}$ & $\begin{array}{lll}20 & 7 & 2,5\end{array}$ & $\begin{array}{lll}6 & 52 & 52,2\end{array}$ & 1,0 & 0,3 \\
\hline Nov. 10 & 7 & Eintr. & $25 \mathrm{~N}$ & $\begin{array}{lll}22 & 13 & 33,4\end{array}$ & $\begin{array}{lll}6 & 57 & 9,1\end{array}$ & 0,3 & 0,5 \\
\hline 13 & 6 & Eintr. & $40 \mathrm{~S}$ & $\begin{array}{lll}22 & 42 & 25,9\end{array}$ & $\begin{array}{lll}714 & 9,2\end{array}$ & 0,3 & 3,0 \\
\hline 21 & $\delta$ geminorum & Einlr. & $8 \mathrm{~N}$ & $\begin{array}{l}04523,6 \\
\end{array}$ & $\begin{array}{lll}8 & 45 & 19,4\end{array}$ & 1,5 & 0,3 \\
\hline & & Austr. & $5 \mathrm{~N}$ & 14024,0 & $\begin{array}{lll}9 & 40 & 10,9\end{array}$ & 1,0 & - \\
\hline 1824 Juny 2 & . . . . & Eintr. & $45 \mathrm{~S}$ & 142626,1 & $941 \quad 20,9$ & 0,2 & 2,0 \\
\hline July 23 & ...$\cdot \cdot$ & Eintr. & $85 \mathrm{~N}$ & $2325 \quad 18,0$ & $1518 \quad 13,2$ & 0,5 & 0,5 \\
\hline & 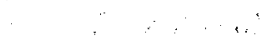 & Austr. & $75 N$ & 233531,0 & 152825,6 & 3,0 & 一 \\
\hline Aug. 5 & $6^{r}$ & Eintr. & $10 \mathrm{~S}$ & $20 \quad 9 \quad 46,6$ & $11 \quad 127,0$ & 2,0 & 2,0 \\
\hline Nov. 29 & $8 \mathrm{ki}$ piscium & Eintr. & $40 S$ & 0 $38 \quad 22,4$ & $\begin{array}{lll}8 & 3 & 53,3\end{array}$ & 0,3 & 2,0 \\
\hline Dec. 26 & 7. 8 & Eints. & $10 \mathrm{~N}$ & 04846,1 & $628 \quad 5,6$ & 0,5 & 0,3 \\
\hline
\end{tabular}

Schwerd.

$Z u$ den in Speier, 1823 und 1824, beobachteten Bedechungen.

1823 . Januar 30.

q Virginis scheinbare Länge $189^{\circ} 1^{\prime} 34^{\prime \prime}, 4$; Breite - $5^{\circ} 19^{\prime} 46^{\prime \prime}, 3$; Conjunction in wahrer Speierer Zeit in der Länge: aus dem Eintr. 17 $41^{\prime} 41^{\prime \prime}, 6+1,65 d B$

woraus $d B=+2^{\prime \prime}, 06$

$$
\text { Austr. } \quad 51,7-3,25 d B
$$

und die verbesserte Conjunction $1741^{\prime} 45,0$

zu Paris nach der conn. des tems 1717 18,8

$$
2426,2
$$

nur um $1 ", 2$ von der bekannten Länge verschieden, welches, mit stündlicher Bewregung $32^{\prime} 43^{\prime \prime}, 0$, die Correction - 0",65 gibt.

\section{März 19.}

Für den ersten Eintritt ist der scheinbare Mondsort AR. $89^{\circ} 5^{\prime}$; Decl. $+26^{\circ} 0^{\prime}$. Den Stern vermochte ich nicht aufzufinden.

Für die vier folgenden Eintritte sind nach der Ordnung die Sterne: hist. cél. p. 310 . 5 $56^{\prime} 27^{\prime \prime}, 5$ trois, Fil; $5^{\text {h }} 58^{\prime} 0^{\prime \prime}, 5 ; 5^{\text {h }} 58^{\prime} 17^{\prime \prime} ; 5^{\text {h }} 58^{\prime} 52^{\prime \prime}$.
An demselben Tage hat Herr Prof. Hallaschka in Prag eilf Eintritte beobachtet - Astr. Nachr. Nr. 37. Für den vierten ist der Stern hist. cél. p. 145. $5^{\text {h }} 53^{\prime} 14^{\prime \prime}$ trois. Fil $=$ p. 310 . $5^{\mathrm{h}} 52^{\prime} 14^{\prime \prime} ;$ der achte stimmt mit Speier II, der zehnte mit Speier III, der eilfte mit Speier IV überein; für die übrigen habe ich keine Sterne gefunden; die scheinbaren Mondsörter für selbige sind, der Ordnung nach, $88^{\circ} 3^{\prime}+26^{\circ} 7^{\prime} ; 88^{\circ} 13^{\prime}+26^{\circ} 6^{\prime}$; $88^{\circ} 17^{\prime}+26^{\circ} 5^{\prime} ; 88^{\circ} 30^{\prime}+26^{\circ} 3^{\prime} ; 89^{\circ} 5^{\prime}+25^{\circ} 58^{\prime} ;$ $89^{\circ} 11^{\prime}+25^{\circ} 57^{\prime} ; 89^{\circ} 21^{\prime}+25^{\circ} 55^{\prime}$. Noch finde ich an diesem Tage einen Eintritt von Herrn Prof. David in Prag beobachtet. - Bode Jahrh. 1827. S. 116 - es ist derselbe Stern wie Hall. IV.

Die Culmination des Mondes ist an diesem Tage beobachtet in Greenwich Nr. 63. der Astr. Nachr.

$$
\text { April } 14 .
$$

Der Stern ist hist. cél. p. 204. $4^{\text {h }} 33^{\prime} 35^{\prime \prime}, 8$; dessen Eintritt ist zugleich in Marseille - conn. d. t. 1827. p. 265 - und in Viviers - corresp. astr. IX, 276 beobachlet Forden; anch hat an demselben Tage Herr 